\title{
ESCRITA E ORALIDADE: HORA E VEZ DA FALA* \\ WRITING AND SPEAKING: THE SPEAKING TIME
}

Aline EMILIO**

Resumo: Neste texto proponho-me, primeiramente, revisitar a história da escrita situando a oralidade; a seguir, com apoio da sociolinguística variacionista, refletir sobre alguns aspectos do funcionamento da língua oral bem como sobre a noção de erro; e, por fim, considerar e sugerir condições para um melhor aproveitamento e desenvolvimento da habilidade oral no ensino de língua materna.

Palavras-chave: Escrita. Oralidade. Ensino.

Abstract: In this text, firstly I'd like to revisit written history situating orality, and secondly within the variational sociolinguistics support to reflect over a few aspects of the function of oral language as well as error notion, and at last, to consider and suggest conditions for a better advantage and development of the oral skill in mother tongue teaching.

Keywords: Written. Orality. Teaching.

\section{INTRODUÇÃO}

Lendo um bilhete:

"Seu Carlos, Favor de comprar cerra, lustra move, ajaque, e foco para a porta da sala que ta queimado. A bassora de barre carçada

* Dedico esse texto aos professores do Ensino Fundamental.

** Lingüista, Doutora pela Universidade Federal de Santa Catarina (UFSC). E-mail: alinemilio@ uol.com.br 
quebro o cabo. No Mufato tem uma boa que eu já vi. A maior sempre atura mais tempo. Tem vitamina das pranta. Já moiei as foiage. Tiau. Marta ."1

O admirável bilhete de Marta reflete uma variedade de escrita própria de uma pessoa que consegue comunicar-se, mesmo transferindo características da oralidade para a escrita. É uma modalidade de escrita que representa, em boa parte, a fala. $\mathrm{O}$ texto traduz $\mathrm{o}$ que temos presenciado, de forma mais branda, em textos até mesmo dos mais letrados. Essa é a razão por que o bilhete de Marta tem a qualidade de fazer a consciência acordar de uma apatia em relação ao ensino da escrita e, principalmente, da oralidade, e encaminharnos para uma reflexão. Para a realização dessa reflexão revisaremos, primeiramente, a posição histórica da escrita e da oralidade; a seguir, esboçaremos um quadro sociolinguístico sobre alguns aspectos da fala e seu funcionamento; após, refletiremos sobre a noção de erro para, finalmente, tratarmos sobre como acreditamos que poderia ser realizado o ensino de língua materna com valorização e aperfeiçoamento da oralidade.

\section{ESCRITA E ORALIDADE: TÚNEL DO TEMPO}

O interagir é tão premente na vida do homem que tem sido tema de vários acontecimentos em todas as épocas. Para ilustrar essa afirmação convido o leitor a buscar na memória, caso tenha assistido ao filme "O Náufrago", cenas em que o ator Tom Hanks, no papel principal, desenha traços do rosto humano, olhos, boca, nariz em uma bola de couro personalizando-a, tal era a sua necessidade de interagir. Conversava com ela em vários momentos, como forma de amenizar o isolamento.

Esse fato mostra que a necessidade individual de se expressar e a necessidade social de se comunicar são duas precisões tão relacionadas que puderam ser notadas já na atitude do homem primitivo. O desenho do homem primitivo sobre a superfície de algum objeto tinha a função de expressar as ideias visualmente, enquanto a fala era sua expressão auditiva. Com o tempo, a expressão visual desenvolveu-se em duas direções distintas: o desenho como arte e o

${ }^{1} \mathrm{O}$ texto-bilhete foi cedido por participante da 'Oficina de Produção de Textos', na Universidade Estadual de Ponta Grossa - UEPG, em 1994, sem a referência. 
sistema pictográfico ${ }^{2}$ na comunicação.

Esse sistema pictográfico não apresentou inicialmente uma relação direta com a fala: porém, encaminhou-se em direção à representação da fala. Assim, a fala representava ideias, e a escrita representava a fala.

Podemos dizer que as etapas evolutivas da história da escrita, segundo Kato (2002, p. 13), foram as seguintes:

\begin{tabular}{|l|}
\hline Inexistência da escrita. \\
\hline Precursores da escrita: fase semasiográfica (sinais) \\
\hline sistema pictográfico (desenho); \\
\hline $\begin{array}{c}\text { recursos de identificação mnemônica (por associação, } \\
\text { por analogia). }\end{array}$ \\
\hline Escrita plena: fase fonográfica (representação dos sons graficamente) \\
\hline lexical-silábica \\
\hline silábica \\
\hline alfabética \\
\hline
\end{tabular}

O período lexical-silábico iniciou por volta de 3100 a C, com o sistema pictográfico, cujas formas sofrem um processo de estilização, para facilitar o traçado, e cujo uso é gradativamente convencionalizado. Os logogramas ou ideogramas ${ }^{3}$ constituem o resultado dessa estilização e convencionalização. A escrita cursiva apareceu bem depois e concorreu à estilização, principalmente por sua tendência de simplificar os traços. O sistema, ao mesmo tempo, deixou de ser icônico ${ }^{4}$, para ser simbólico ${ }^{5}$. O logograma já possuía estatuto linguístico de palavra, portanto, tinha também sua representação fonética.

A passagem para o sistema silábico mostra um fenômeno, conforme Kato (op. cit., p. 15), conhecido como rébus, que é a representação de palavras ou sílabas por pictogramas, utilizando-se apenas os sons dos nomes dos objetos representados. Tomemos, por exemplo, o desenho de uma carinha para representar "cara" e o pictograma, ou desenho, de um barquinho com vela para representar "vela". Da composição com eles temos a palavra caravela, e estaremos usando apenas as propriedades fonéticas e não as semânticas. Segundo a

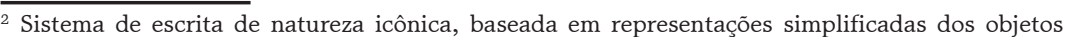
da realidade.

${ }^{3}$ Letras de forma.

${ }^{4}$ Propriedade do signo de representar o mundo real.

${ }^{5}$ Aquilo que, por um princípio de analogia, representa ou substitui outra coisa.
} 
autora, esse foi o caminho encontrado pelo homem para descobrir a escrita silábica.

Foi o espírito prático de comerciantes dos fenícios que fez com que se apossassem da complicada escrita lexical-silábica dos egípcios, originária dos hieróglifos, e dela extraíssem 24 símbolos, para formar o silabário. Esse silabário constituía-se de consoantes; as semiconsoantes $/ \mathrm{w} / \mathrm{e} / \mathrm{y} /$ serviam, raramente, para representar as vogais $/ \mathrm{u} / \mathrm{e} / \mathrm{i} /$.

Para construção do alfabeto os gregos tomaram emprestado o silabário fenício, como base de sua escrita. Mas a colocação da vogal depois de consoante firmou-se, entre eles, como norma. Passou-se assim da escrita silábica para a escrita alfabética. A descoberta do alfabeto aconteceu no século X a C. Após essa descoberta, nenhuma inovação significativa ocorreu na história da escrita. Quando o homem começou a usar um símbolo para cada som, ele apenas operou conscientemente com o seu conhecimento da organização fonológica de sua língua.

Como se pode perceber, a natureza da nossa ortografia é alfabética. Na escrita, os sons que essencialmente constituem a linguagem passam a ser evocados mentalmente por meio de símbolos gráficos.

Nessa breve contextura evolutiva não é de admirar que a civilização tenha dado importância extraordinária à escrita. No entanto, é preciso não perder de vista que mais antiga, mais básica, é a expressão oral. A rigor, a linguagem escrita não passa de um sucedâneo. Ainda mais se pensarmos que a escrita registra milênios de tradição, enquanto que a fala compreende centenas, senão milhares de anos, considerando-se o registro do homem na terra em mais ou menos três milhões de anos. Pode-se dizer que a expressão oral é que abrange a comunicação linguística em sua totalidade, pressupondo, além da significação dos enunciados, o timbre de voz, a entoação, os elementos subsidiários da mímica, incluindo-se aí o jogo fisionômico, recursos considerados eficazes para realização da intenção comunicativa.

Não há como negar que as manifestações linguísticas deram-se e dão-se, em sua maioria, na forma oral. Entre as várias funções da manifestação oral nas comunidades está a de preencher as horas de lazer, desenvolver as "mnemonias", dar orientação moral ou ensinar através da sabedoria popular como acontece nos provérbios, por seu valor argumentativo: "A pressa é inimiga da perfeição", "Quem planta colhe", "Um homem prevenido vale por dois", entre outros. 
Isso leva a crer que para bem se compreender a natureza e o funcionamento da linguagem, é preciso partir da apreciação da linguagem oral, valorizar a fala, utilizá-la como ritual de passagem para orientar a escrita.

Pensar dessa forma encaminha-nos para os estudos da Sociolinguística, que tem como interesse central o emprego concreto da língua; em outras palavras, preocupa-se com os aspectos relacionados à fala.

SOCIOLINGUÍSTICA: TEMPO DE VALORIZAR A ORALIDADE

É comum afirmar-se que a Sociolinguística estuda a língua em uso nas comunidades de fala. Igualmente corriqueiro consiste em assinalar que sua atenção está voltada para um tipo de investigação que correlaciona aspectos dos sistemas linguísticos a aspectos dos sistemas sociais. O fato é que é impossível desvincular a língua de sua função sócio-comunicativa. Entende-se então a Sociolinguística como um espaço de investigação interdisciplinar, que atua nas fronteiras entre língua e sociedade, focalizando os empregos concretos da língua e, consequentemente, a heterogeneidade linguística.

Não é raro encontrar-se mais de uma forma equivalendo a um mesmo significado, ao nível do vocabulário, da morfossintaxe, da semântica ou da fonética e da fonologia de uma língua. Isso é o que se denomina de variável linguística. Em outras palavras, são duas ou mais formas distintas de transmitir um conteúdo informativo. Já as formas alternantes, que expressam a mesma coisa num mesmo contexto, são denominadas de variantes linguísticas; são idênticas quanto à referência, mas opostas em sua significação social. Não há diferença semântica, por exemplo, se pronunciarmos a primeira pessoa do singular do indicativo presente dos verbos dar, ser e estar com ou sem ditongo.

O português falado está repleto de exemplos. No sul do país, mais especificamente no Rio Grande do Sul e em Santa Catarina, o pronome tu é o tratamento preferido quando o locutor interage com o interlocutor, situação que difere da maioria das regiões do país, em que você é mais empregado. A presença de concordância nominal e verbal como em "os meninos bagunceiros" e "eles estudam português" em geral alterna-se com a possibilidade de ocorrência de enunciados em 
que tais marcas estão ausentes: "os menino bagunceiro", "eles estuda português". A realização de "bassora", "barre", "carçada", "quebro", "pranta" "moiei", "foiage" "ta", como no bilhete de Marta, ou ainda de "Cráudia", "chicrete" "andano", , "falá", "paia" "célebro" é encontrada coexistindo com "vassoura", "calçada", quebrou", "planta" , "molhei”, "folhagem" "está", "Cláudia", "chiclete" "andando", "está", "falar", "palha" "cérebro". Construções sintáticas como "eu vi ela ontem", "nós fomos no cinema", "é o tipo de assunto que eu não gosto dele" estão presentes no português, alternando com os equivalente semânticos "eu a vi ontem", "nós fomos ao cinema", "é o tipo de assunto de que eu não gosto". Esses são alguns dos numerosos exemplos que ilustram a variabilidade da língua.

A Sociolinguística preocupa-se exatamente com essa variação, entendendo-a como um princípio geral e universal das línguas, passível de ser analisada e descrita. Conforme Bagno (2002), tal variação linguística pode dar-se no eixo diatópico, no eixo diastrático e no eixo diacrônico. No primeiro, as alternâncias se expressam regionalmente; no segundo, elas se manifestam de acordo com os diferentes estratos sociais; no terceiro, elas se manifestam nas diferentes faixas etárias.

Sob essas perspectivas, a variação é contínua e, em nenhuma hipótese, é possível demarcar nitidamente localizações geográficas e sociais ou momentos em que ela ocorre. É preferível falar em tendências a empregos de certas formas, as quais são motivadas por condicionamentos diversos.

\section{EM TEMPO: A NOÇÃO DE "ERRO"}

“... juízo falso, desacerto, engano ..." (FERREIRA, 1986, p. 679) estão entre as definições de "erro". Será que as variedades de linguagem podem enquadrar-se nessas definições? Se nos remetermos ao bilhete de Marta, vamos acreditar que não. Entendemos que seu ato comunicativo se concretiza através da escrita, porque ela acredita no seu juízo verdadeiro, no seu acerto, na realização da intenção e, de fato, é possível perceber que a intenção comunicativa se efetiva, o que nos leva a repensar a noção de "erro", principalmente quando se trata de ensino.

Considerando as variedades linguísticas, o professor passa a ter a responsabilidade de apresentar aos alunos os valores sociais 
atribuídos a cada variedade linguística. Dizemos isso, porque somos todos conhecedores de que a língua é com frequência usada na prática da discriminação, da exclusão social. O preconceito linguístico é uma realidade inegável. Talvez possamos atribuir parte do preconceito à crença de que existe um modelo ideal de língua.

Uma vez consciente dessa situação problemática o professor deverá apoderar-se dos resultados oferecidos pela pesquisa sociolinguística e pelas teorias lingüísticas de inspiração não-idealista como apoio para seu exercício pedagógico.

Vários estudiosos, entre eles Bagno (1999, 2002), Lemle (2001), Silva e Moura (2002) são defensores da ideia de que não existe erro em língua, o que existe de fato é variação e mudança. As línguas por natureza não mudam para melhor ou pior, elas não progridem nem se deterioram, elas naturalmente variam e mudam. Por essa razão, tudo o que é classificado tradicionalmente como "erro" tem uma explicação científica perfeitamente demonstrável. Vejamos:

No caso da gíria "sujou" para se referir a um evento inesperado, de eventual risco, temos uma prática caracterizada por alguns traços sintáticos como a utilização de verbo transitivo como intransitivo.

- No caso de "véio", correspondente a "velho", até pouco tempo considerado uso próprio de falantes da área rural, hoje já faz parte do vocabulário do falante da área urbana em expressões como "meu véio viajou" ou "e aí, véio?". Ocorre aí uma prática caracterizada por traços fonéticos, denominada de despalatalização.

- No caso de "caxa" "pêxe" "amexa", correspondentes a "caixa", "peixe" e "ameixa", temos o fenômeno da monotongação. Devemos atentar para o fato de que esse fenômeno atinge também o falante de norma urbana culta, ou seja, aquele falante que possui curso universitário e reside na área urbana.

- Na transformação de $\mathbf{l}$ por $\mathbf{r}$ nos encontros consonantais como "pranta" "praca", estamos diante de um fenômeno fonético que contribuiu para a formação da própria língua portuguesa, como nos informa Bagno (1999, p. 41): no Português padrão, "branco" originou-se de "blank", de origem germânica; o mesmo aconteceu com "cravo", de "clavu", do latim; ou "prata", de "plata" também do latim; "praga", de "plaga", entre outras palavras. Como se pode ver, todas tinham um l na sua origem que se transformou em $\mathrm{r}$. $\mathrm{O}$ autor argumenta que 
se pensarmos que quem diz "chicrete", "Cráudia", "pranta", "praca" tem atraso mental, seríamos forçados a admitir que a população da província romana da Lusitânia também sofria desse problema na época em que a língua portuguesa estava se formando.

No entanto, do ponto de vista sociológico o erro existe e sua maior ou menor gravidade depende da distribuição dos falantes na pirâmide das classes sociais, que é também uma pirâmide de variedades linguísticas. Quanto mais baixo estiver um falante na escala da pirâmide social, maior número de "erros" as camadas mais elevadas atribuirão à sua variedade linguística. $\mathrm{O}$ "erro" linguístico, do ponto de vista sociológico e antropológico, é baseado no valor social atribuído ao falante. Essa avaliação é realizada de acordo com o poder aquisitivo, o grau de escolarização, a renda mensal, a origem geográfica, a cor da pele, o sexo, entre outros critérios e preconceitos socioeconômicos e culturais.

É fácil perceber que do ponto de vista linguístico, não há diferença funcional entre dizer "aquelas coisa toda" e "aquelas coisas todas", mas do ponto de vista social a regra gramatical - eliminar plurais redundantes - presente também em "os menino canta", é avaliada como "erro".

Desse modo, uma das tarefas do ensino de língua na escola é discutir os valores sociais atribuídos a cada variante linguística, enfatizando a carga de discriminação que pesa sobre determinados empregos da língua, de modo a conscientizar o aluno de que sua produção lingüística, oral ou escrita, está sujeita a uma avaliação social, positiva ou negativa. Se, num trabalho escrito, por exemplo, encontramos usos condenados pela gramática normativa - como os do bilhete de Marta, por exemplo - devemos ter a honestidade e o bomsenso de reconhecer que a "norma padrão" tradicional oferece apenas uma das muitas possibilidades de realização dos recursos existentes na língua. O que devemos fazer é mostrar ao aluno que essa é uma opção entre tantas opções possíveis, que tem sua funcionalidade de acordo com a situação temporal, espacial, social, cultural.

\section{ORALIDADE - NOVOS TEMPOS: HORA E VEZ DA FALA}

A atividade pedagógica tem subjacente, de forma explícita ou intuitiva, uma determinada concepção de linguagem. É preciso que 
se tenha presente que toda e qualquer metodologia de ensino articula uma opção política - que envolve uma teoria de compreensão e interpretação da realidade - com os mecanismos utilizados em sala de aula. A prática de sala de aula é dependente dessa opção, a partir da qual as questões linguísticas são percebidas. Assim, os conteúdos, o enfoque, as estratégias de trabalho, a bibliografia, o sistema de avaliação, o relacionamento, tudo isso corresponde, nas nossas atividades de sala de aula, ao caminho por que se optou.

Os estudos linguísticos mostram duas grandes tendências para tratar os fatos de linguagem: uma tendência centrada na língua, enquanto conjunto abstrato de signos e regras, desvinculado de suas condições de realização; e, outra, centrada na língua enquanto atuação social, enquanto atividade de interação verbal entre interlocutores, vinculada, portanto, às condições de realização.

Consideradas as tendências e partidários de uma concepção de linguagem como interacional, fica claro que nos vinculamos à segunda tendência. Vincular-se a essa tendência e assumir a dimensão interacional de linguagem é acreditar na possibilidade de uma consideração mais ampla da linguagem e de um trabalho pedagógico mais produtivo.

Acreditamos que uma concepção interacionista de linguagem, funcional e contextualizada, pode fundamentar um ensino da língua que seja, individual e socialmente, produtivo. Além disso, que seja relevante no que diz respeito ao trato da oralidade, pois valorizar a individualidade é respeitar a variedade linguística mesmo quando afastada dos ditames da gramática e do dicionário.

Os próprios Parâmetros Curriculares Nacionais do Ensino Médio e, principalmente, os do Ensino Fundamental contemplam, nas suas orientações, a questão da oralidade, como se pode constatar no fragmento transcrito a seguir:

Expressar-se oralmente é algo que requer confiança em si mesmo. Isso se conquista em ambientes favoráveis à manifestação do que se pensa, do que se sente, do que se é. Assim, o desenvolvimento da capacidade de expressão oral do aluno depende consideravelmente da escola constituir-se num ambiente que respeite e acolha a vez e a voz, a diferença e a diversidade. Mas, sobretudo, depende de a escola ensinar-lhe os usos da língua adequados a diferentes situações comunciativas. (BRASIL, 1997, p. 49). 
Desse modo, entendemos que o objeto de análise na escola deveria privilegiar usos reais e próprios da fala brasileira, nas mais diversas situações de emprego, pois se o aluno é o sujeito da aprendizagem, é ele quem realiza, na interação com o objeto da aprendizagem, a atividade estruturadora da qual resulta o conhecimento.

Assumimos, portanto, com Antunes (2003, p. 42), uma concepção "interacionista, funcional e discursiva da língua, da qual deriva o princípio geral de que a língua só se atualiza a serviço da comunicação intersubjetiva, em situações de atuação social e através de práticas discursivas, materializadas em textos orais...".

$\mathrm{Na}$ dimensão interacional de linguagem, deve-se chamar a atenção para o fato de como se concebe a oralidade. A oralidade serve à interação verbal, assim como a escrita, sob a forma de diferentes gêneros textuais, na diversidade dialetal e de registro que qualquer uso da linguagem implica. Não tem sentido a ideia da fala apenas como lugar de espontaneidade, do relaxamento, da falta de planejamento e do descuido em relação às normas de planejamento e até o descuido em relação às normas da língua padrão. A fala pode variar: pode estar mais, ou menos, planejada; mais, ou menos, cuidada em relação à norma padrão; pode ser mais, ou menos, formal, conforme for o contexto de uso.

Assumir essa concepção interacionista, funcional e discursiva de língua não permite, portanto, omitir a fala como objeto de exploração no trabalho de sala de aula; entendê-la como lugar para violar as regras da gramática; limitar-se apenas ao gênero informal da oralidade. Assim, promover o desenvolvimento comunicativo do aluno implica não restringir a visão de que a fala só serve para errar e conversar, implica dar à fala papel central no ensino de língua materna e, a partir daí, promover o desenvolvimento do aluno na compreensão e análise do funcionamento dos aspectos envolvidos na oralidade em relação à escrita.

Nas salas de aula deveria haver espaço para traçar um paralelo entre oralidade formal e informal, para a abordagem dos gêneros orais que solicitam registros formais com uso de léxico especializado e estrutura textual mais rígida, para o atendimento a certas convenções sociais ao se falar em público.

O que se tem evidenciado no ensino é a falta de oportunidades para desenvolver habilidades orais, porém esse quadro pode ser amenizado se o ensino de língua materna promover a orientação para 
atividades capazes de desenvolver, de fato, habilidades linguísticas aproveitando o que o aluno já domina.

Por essas razões o próximo passo é sugerir algumas atividades, já utilizadas em nossa prática de sala de aula, que contribuíram para o aperfeiçoamento da competência oral dos alunos. Inicialmente, o aluno deve ser orientado para a atividade de reconhecer e saber diferenciar os vários gêneros dos textos orais como: conversa coloquial, conversa formal, palestra, convite, aviso, debate, sermão, entrevista, discurso, entre outros; na sequência, aprender a identificar o tema das manifestações linguísticas e perceber que esse tema se desenvolve através de tópicos e subtópicos e que entre eles há um encadeamento. Elegemos esses itens tendo em vista que eles sintetizam a superestrutura ${ }^{6}$ do texto oral.

Entendemos que ter uma visão da estrutura global semântica do texto através da identificação do gênero, da identificação do assunto, seus tópicos e subtópicos facilita ao aluno explorar outras unidades integrantes da fala formal e informal, como a polidez, a cooperação, a participação na interlocução, o ouvir; somam-se a essas unidades a entonação, pausas, gestos, fisionomia e, principalmente, o sentido que se constrói também dos implícitos. O conhecimento da implicação funcional desses elementos na atividade de comunicação contribui para uma interação adequada às exigências sociais e culturais.

O desenvolvimento dessas atividades supõe saberes e conteúdos, o que significa dizer que o professor deve buscar recursos, subsídios informativos não só da linguística, mas de outras áreas que poderão servir de suporte para que realize discussões e reflexões consistentes em sala de aula.

Quanto aos recursos para desenvolver a habilidade oral do aluno, são os mais diversos possíveis. Entre eles sugerimos assistir a filmes, contar histórias, relatar fatos, argumentar, refutar, criticar opiniões, expor programações, fazer convites, dramatizar produções próprias, fazer entrevistas. Enfim, são muitos os recursos e meios que contribuem, significativamente, para o desenvolvimento da oralidade, mas é relevante lembrar que o seu uso depende, sobretudo, da competência e da criatividade do professor. O importante é ter em mente que a escola precisa abrir-se para todos os gêneros da oralidade que concretizam o uso da língua.

${ }^{6}$ Superestrutura, conforme Van Dijk (1992), é um complexo de categorias e regras de formação que determinam a ordem global das partes do texto. 
Escrita e oralidade: hora e vez da fala

\section{CONSIDERAÇÕES FINAIS}

Valorizar a oralidade é pôr em xeque os valores de ensino tradicional. É inaugurar uma nova atitude na forma de ensinar. É ensinar no mesmo tom e compasso de viver, como tão bem traduz o bilhete de Marta.

Sem dúvida, alunos vão ficar sem saber as minúcias gramaticais, mas muitos deles saberão dizer coisas com sentido e do jeito que a situação social pede que se diga. E, então, teremos autores. Alunos que têm uma palavra a dizer e sabem como dizer, o que implica o desenvolvimento de habilidades que se referem ao plano imediato do saber fazer.

O ensino, com foco nas habilidades, permite o desenvolvimento de processos gerais de raciocínio, em lugar de contemplar-se a memorização de conteúdos. Alunos mais capazes para dizer terão mais facilidade de ler e escrever e, consequentemente, de atuarem melhor na sociedade. Portanto, valorizar a oralidade é uma das formas de aproximar o estudo da língua do ideal de "competência", ou de "competência para a cidadania".

\section{REFERÊNCIAS}

ALKMIN, T. Sociolingüística. Parte 1. In: MUSSALIN, F.; BENTES, A. C. (Orgs.). Introdução à linguística: domínios e fronteira. São Paulo: Cortez, 2001.

ANTUNES, I. Aula de português: encontro e interação. São Paulo: Parábola , 2003.

BAGNO. M. Preconceito lingüístico: o que é, como se faz. São Paulo: Loyola, 1999.

M. Português ou brasileiro?: um convite à pesquisa. São Paulo: Parábola, 2002.

BORTONI-RICARDO, S. M. Educação em língua materna: a sociolingüística na sala de aula. São Paulo: Parábola Editorial, 2004.

BAKHTIN, M. Marxismo e filosofia da linguagem. São Paulo: Hucitec, 1997.

BRASIL. Ministério de Educação e Cultura. Parâmetros curriculares nacionais: primeiro e segundo ciclos - língua portuguesa. Brasília: MEC/SEF, 1997.

414 Olhar de professor, Ponta Grossa, 11(2): 403-415, 2008.
Disponível em < 4 http://www.uepg.br/olhardeprofessor> 
. Ministério de Educação e Cultura. Parâmetros curriculares nacionais: terceiro e quarto ciclos - língua portuguesa. Brasília: Secretaria de Educação Fundamental. Brasília: MEC/SEF, 1998.

CALVET, L. J. Sociolingüística: uma introdução crítica. Tradução de Marcos Marcionilo. São Paulo: Parábola, 2002.

CAMACHO, R. G. Sociolingüística. Parte 2. In: MUSSALIN, F.; BENTES, A. C. (Orgs.). Introdução à lingüística: domínios e fronteiras. São Paulo: Cortez, 2001.

FERREIRA, A. B. H. Novo dicionário da língua portuguesa. Rio de Janeiro: Nova Fronteira, 1986.

ILARI, R. A lingüística e o ensino da língua portuguesa. São Paulo: Martins Fontes, 1997.

KATO, M. A. No mundo da escrita: uma perspectiva psicolingüística. São Paulo: Ática, 2002.

LEMLE, M. Guia teórico do alfabetizador. São Paulo: Ática, 2001.

MARCUSCHI, L. A . Análise da conversação. São Paulo: Ática, 1999.

SILVA, F. L. e MOURA, H. M. M. (orgs). O direito à fala: a questão do preconceito. Florianópolis: Insular, 2002.

TRAVAGLIA. L. C. Gramática e interação: uma proposta para o ensino de gramática $1^{\circ}$ e $2^{\circ}$ graus. São Paulo: Cortez, 1998.

VAN DIJK, T. A. Cognição, discurso e interação. São Paulo: Contexto, 1992.

Enviado em: 03/08

Aceito em: 08/08 